\title{
Hydrogen-storage materials for mobile applications
}

\author{
Louis Schlapbach*† \& Andreas Züttel† \\ *EM PA, Swiss Federal Laboratories for M aterials Research and Testing, CH - 8600 Dübendorf, Switzerland \\ †University of Fribourg, Physics D epartment, CH - 1700 Fribourg, Switzerland (e-mail: andreas.zuettel@unifr.ch)
}

Mobility - the transport of people and goods - is a socioeconomic reality that will surely increase in the coming years. It should be safe, economic and reasonably clean. Little energy needs to be expended to overcome potential energy changes, but a great deal is lost through friction (for cars about $10 \mathrm{kWh}$ per 100 $\mathrm{km}$ ) and low-efficiency energy conversion. Vehicles can be run either by connecting them to a continuous supply of energy or by storing energy on board. Hydrogen would be ideal as a synthetic fuel because it is lightweight, highly abundant and its oxidation product (water) is environmentally benign, but storage remains a problem. Here we present recent developments in the search for innovative materials with high hydrogen-storage capacity.

mer
enect
electron rgy can be stored in different forms: as echanical energy (for example, potential hergy or rotation energy of a flywheel); in an lectric or magnetic field (capacitors and coils, pectively); as chemical energy of reactants and fuels (batteries, petrol or hydrogen); or as nuclear fuel (uranium or deuterium). Chemical and electric energy can be transmitted easily because they both involve electronic Coulomb interaction. Chemical energy is based on the energy of unpaired outer electrons (valence electrons) eager to be stabilized by electrons from other atoms. The hydrogen atom is most attractive because its electron (for charge neutrality) is accompanied by only one proton. Hydrogen thus has the best ratio of valence electrons to protons (and neutrons) of all the periodic table, and the energy gain per electron is very high.

$\mathrm{H}$ ydrogen is the most abundant element on Earth, but less than $1 \%$ is present as molecular hydrogen gas $\mathrm{H}_{2}$. The overwhelming majority is chemically bound as $\mathrm{H}_{2} \mathrm{O}$ in water and some is bound to liquid or gaseous hydrocarbons. The clean way to produce hydrogen from water is to use sunlight in combination with photovoltaic cells and water electrolysis (see review in this issue by Grätzel, pages 338-344). Other forms of primary energy and other water-splitting processes are also used: the hydrogen consumed today as a chemical raw material (about $5 \times 10^{10} \mathrm{~kg}$ per year worldwide) is to a large extent produced using fossil fuels and the reaction of hydrocarbon chains $\left(-\mathrm{CH}_{2}^{-}\right)$with $\mathrm{H}_{2} \mathrm{O}$ at high temperatures, which produces $\mathrm{H}_{2}$ and $\mathrm{CO}_{2}$. Direct thermal dissociation of $\mathrm{H}_{2} \mathrm{O}$ requires temperatures higher than $2,000{ }^{\circ} \mathrm{C}$ ( $>900{ }^{\circ} \mathrm{C}$ with a Pt/Ru catalyst).

Thechemical energy per mass of hydrogen $\left(142 \mathrm{M} \mathrm{J} \mathrm{kg}^{-1}\right)$ is at least threetimeslarger than that of other chemical fuels (for example, the equivalent value for liquid hydrocarbons is $47 \mathrm{MJ} \mathrm{kg}^{-1}$ ). Once produced, hydrogen is a clean synthetic fuel: when burnt with oxygen, the only exhaust gas is water vapour, butwhen burnt with air, lean mixtureshaveto beused to avoid theformation of nitrogen oxides. Whether hydrogen can be considered a clean form of energy on a global scale depends on theprimary energy that isused to split water ${ }^{1}$.

The availability of free energy is often unsafe. The mechanical energy of a 1,000-kg car running out of control at $40 \mathrm{~km} \mathrm{~h}^{-1}$ can kill pedestrians. The process of burning hydrogen can bedone in an efficient and controlled way to liberateenergy at a desirablerate, or in an uncontrolled way with the potential to cause damage. For historical reasons hydrogen has a bad reputation, which is not altogether justified: a morerecent analysis ${ }^{2}$ of theH indenburg catastrophe shows that the air ship caught fire because of a highly flammable skin material and not because of the hydrogen gas it contained. The safety of hydrogen relies on its high volatility and non-toxicity.

Today, many scientists and engineers, some companies, governmental and non-governmental agencies and even finance institutions are convinced that hydrogen's physical and chemical advantages will make it an important synthetic fuel in the future. After thesuccessful use of hydrogen for space technology, national hydrogen associations were created and joint ventures started. Examples are fuel-cell development projects, the Shell-GfE-HydroQuébec joint venture ${ }^{3}$, the International Hydrogen Energy Association and its technical-economic conferences, and solar hydrogen $R \& D$ programmes. But are these ventures aimed at mobility?

There are essentially two ways to run a road vehicle on hydrogen. In the first, hydrogen in an internal combustion engineis burnt rapidly with oxygen from air. The efficiency of thetransformation from chemical to mechanical through thermal energy is limited by the Carnot efficiency and is slightly higher for hydrogen-air mixtures (around 25\%) than for petrol-air mixtures. When a lean mixture is used, the exhaust gas contains nothing but water vapour; richer mixtures also produce $\mathrm{NO}_{x}$. In the second method, hydrogen is 'burnt' electrochemically with oxygen from air in a fuel cell, which produceselectricity (and heat) and drivesan electric engine(seereview in thisissueby Steeleand H einzel, pages 345-352). H ere, the efficiency of the direct process of electron transfer from oxygen to hydrogen is not limited by the Carnot efficiency; it can reach 50-60\%, twice asmuch as thethermal process.

For on-board energy storage, vehicles need compact, light, safe and affordable containment. A modern, commercially available car optimized for mobility and not prestigewith arange of $400 \mathrm{~km}$ burnsabout $24 \mathrm{~kg}$ of petrol in acombustion engine; to cover thesamerange, $8 \mathrm{~kg}$ hydrogen 


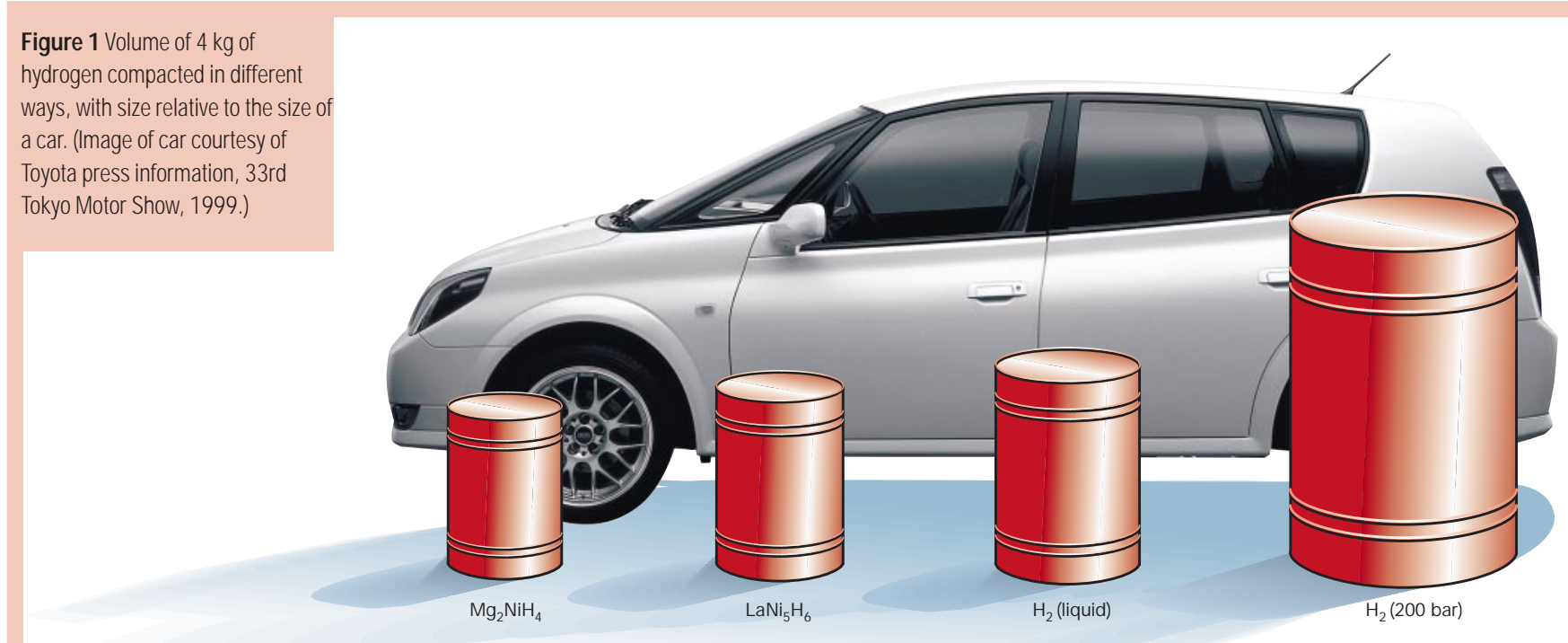

are needed for the combustion engine version or $4 \mathrm{~kg}$ hydrogen for an electric car with afuel cell.

Hydrogen is a molecular gas. At room temperature and atmospheric pressure, $4 \mathrm{~kg}$ of hydrogen occupies a volume of $45 \mathrm{~m}^{3}$. This corresponds to a balloon of $5 \mathrm{~m}$ diameter - hardly a practical solution for a vehicle (Table 1). In the following we will focus on thequestion of compacting hydrogen, looking at thematerials, technology and safety aspects (Fig. 1).

\section{Conventional hydrogen storage}

Classical high-pressuretanksmadeof fairly cheap steel aretested up to $300 \mathrm{bar}$ and regularly filled up to $200 \mathrm{bar}$ in most countries. To store our $4 \mathrm{~kg}$ hydrogen still requiresan internal volumeof 225 litres (about 60 gallons) or 5 tanks of 45 litreseach. Novel high-pressuretanksmade of carbon-fibre-reinforced compositematerials are being developed; thesearetested up to 600 bar and filled up to 450 bar for regular use. But they need a special inert inner coating to prevent the highpressurehydrogen reacting with the polymer. Consequently, another approach is to usehydrogen-inert aluminium tanksand to strengthen them with external carbon-fibrecoatings. Spherical containers slightly smaller than $60 \mathrm{~cm}$ in diameter would beableto carry our $4 \mathrm{~kg}$, but for practical fabrication acylindrical shapeisprefer red.

These high-pressure containers, when full, would contain about $4 \%$ hydrogen by mass, but with significant disadvantages: the fuel would be availableat a pressure dropping from 450 bar to zero overpressure, so additional pressure control would be essential. High-pressurevessels present a considerablerisk - thecompression itself is the most dangerous and complicated part. In Japan such vesselsareprohibited on theroadsin ordinary cars. .

Condensation into liquid or even solid hydrogen is, of course, particularly attractive from the point of view of increasing the mass

\begin{tabular}{|c|c|c|c|}
\hline Properties & Hydrogen $\left(\mathrm{H}_{2}\right)$ & Methane $\left(\mathrm{CH}_{4}\right)$ & Petrol $\left(-\mathrm{CH}_{2}-\right)$ \\
\hline Lower heating value $\left(\mathrm{kWh} \mathrm{kg}^{-1}\right)$ & 33.33 & 13.9 & 12.4 \\
\hline Self-ignition temperature $\left({ }^{\circ} \mathrm{C}\right)$ & 585 & 540 & $228-501$ \\
\hline Flame temperature $\left({ }^{\circ} \mathrm{C}\right)$ & 2,045 & 1875 & 2,200 \\
\hline Ignition limits in air (Vol\%) & $4-75$ & $5.3-15$ & $1.0-7.6$ \\
\hline Minimal ignition energy (mW s) & 0.02 & 0.29 & 0.24 \\
\hline Flame propagation in air $\left(\mathrm{m} \mathrm{s}^{-1}\right)$ & 2.65 & 0.4 & 0.4 \\
\hline Diffusion coefficient in air $\left(\mathrm{cm}^{2} \mathrm{~s}^{-1}\right)$ & 0.61 & 0.16 & 0.05 \\
\hline Toxicity & No & No & High \\
\hline
\end{tabular}

per container volume. The density of liquid hydrogen is $70.8 \mathrm{~kg} \mathrm{~m}^{-3}$ ( $70.6 \mathrm{~kg} \mathrm{~m}^{-3}$ for solid hydrogen). But the condensation temperature of hydrogen at 1 bar is $-252^{\circ} \mathrm{C}$ and the vaporization enthalpy at the boiling point amounts to $452 \mathrm{~kJ} \mathrm{~kg}^{-1}$. As the critical temperature of hydrogen is $-241^{\circ} \mathrm{C}$ (above this temperature hydrogen is gaseous), liquid hydrogen containers are open systems to prevent strong overpressure. Therefore, heat transfer through the container leads directly to theloss of hydrogen. Larger containers havea smaller surfaceto volumeratio than small containers, so the loss of hydrogen is smaller. The continuously evaporated hydrogen may becatalytically burnt with air in the overpressure safety system of the container or collected again in a metal hydride. (Solid hydrogen is a molecular insulating solid; under high pressure it transforms into metallic, possibly even superconducting hydrogen ${ }^{4}$ with $\mathrm{T}_{\mathrm{c}}$ of $200-300^{\circ} \mathrm{C}$.)

Cryotechniques for cooling and superinsulated low temperature storageunits weredeveloped and proven in spacetechnology. Liquid hydrogen is afuel in thelaunching process of theSpaceShuttleand in Ariane. A Lockheed military-type aircraft and a Tupolev supersonic aircraft have been flown with engines fuelled by liquid hydrogen. BM W have built an automated liquid-hydrogen filling station, and developed and tested several cars running with hydrogen in newly designed vessels to reduce losses by evaporation to below 1.5 mass\% per day (BM W, personal communication).

$\mathrm{H}$ ydrocarbons with a molecular mass of at least $60 \mathrm{~g} \mathrm{~mol}^{-1}$ are liquid at room temperature with a density close to $1,000 \mathrm{~kg} \mathrm{~m}^{-3}$. The number of hydrogen atoms per carbon atom can vary in hydrocarbons owing to their ability to change from $\sigma$-bonds to $\pi$-bonds. Hydrocarbons can be burnt completely by oxidation of carbon into $\mathrm{CO}_{2}$ and of hydrogen into $\mathrm{H}_{2} \mathrm{O}$; some can also be considered as a liquid storagemedium for hydrogen if they can behydrogenated and dehydrogenated; that is, if their ratio of hydrogen to carbon atoms can be adapted reversibly. Cyclohexane $\left(\mathrm{C}_{6} \mathrm{H}_{12}\right)$, for example, reversibly desorbs six hydrogen atoms (7.1 mass\%) and forms benzene $\left(\mathrm{C}_{6} \mathrm{H}_{6}\right)$. Stationary hydrogenation and dehydrogenation under steady-state conditions are managed in numerous chemical plants, but theon-board processunder variableconditionsisanother matter. We do not consider hydrogen storage in $\mathrm{NH}_{3}(5.9$ mass\%) to berealistic, owing to thecorrosivenature of ammonia.

\section{Hydrogen adsorption on solids of large surface area}

Hydrogen adsorbs at solid surfaces depending on the applied pressureand thetemperature. Thevariation of attractivesurfaceforcesas a function of distance from the surface decides whether van der 
Waals-type weak physisorption of molecular hydrogen occurs, or whether dissociation and chemisorption of atomic hydrogen takes place. O wing to the attractive forces, the most stable position for an adsorbed moleculeiswith its centreat about 1 molecular radiusfrom the surface, and the attractive field rapidly diminishes at greater distances. Once a monolayer of adsorbate molecules or atoms has formed, the gaseous species interacts with the liquid or solid adsorbate. Therefore, thebinding energy of the second layer of adsorbates is similar to the latent heat of sublimation or vaporization of the adsorbate. Consequently, adsorption at atemperatureat or abovethe boiling point of theadsorbate at a given pressure leads to theadsorption of a single monolayer. For storage purposes, the adsorption of hydrogen has been studied on carbon species only. Other light and reasonably cheap materials of high surface area may prove to be attractiveaswell.

The condensation of a monolayer of hydrogen on a solid leads to a maximum of $1.3 \times 10^{-5} \mathrm{~mol} \mathrm{~m}^{-2}$ of adsorbed hydrogen. In thecase of a graphene sheet with a specific surface area of $1,315 \mathrm{~m}^{2} \mathrm{~g}^{-1}$ as adsorbent, themaximum theoretical concentration is $0.4 \mathrm{H}$ atomsper surfacecarbon atom or 3.3 mass $\%$ hydrogen on sheets with hydrogen atoms on one side. On active carbon with the specific surface area of $1,315 \mathrm{~m}^{-2} \mathrm{~g}^{-1}, 2$ mass\% hydrogen is reversibly adsorbed at a temperature of $77 \mathrm{~K}$ (ref. 4). On nanostructured graphitic carbon at $77 \mathrm{~K}$ (liquid nitrogen temperature), the reversibly adsorbed quantity of hydrogen correlates with the specific surface area of the sample. It amountsto 1.5 mass $\%$ per $1,000 \mathrm{~m}^{2} \mathrm{~g}^{-1}$ of specific surfacearea (Fig. 2), in agreement with the calculation shown in Fig. 3. Nanostructured graphite produced by ball milling for $80 \mathrm{~h}$ in a 1-M Pa hydrogen atmosphere contains up to $0.95 \mathrm{H}$ atoms per carbon atom or 7.4 mass $\%$. Eighty per cent of this hydrogen desorbsat a temperature of over $600 \mathrm{~K}$. Evidently, moderately high hydrogen absorption can be realized with planar graphitic structuresat low temperature,8.

Are curved structures more attractive? In microporous solids with capillaries which have a width not exceeding a few molecular diameters (the diameter of $\mathrm{H}_{2}$ is $0.41 \mathrm{~nm}$ ), the potential fields from oppositewalls overlap so that the attractive forceacting on hydrogen molecules is greater than that on an open flat surface. The effect of nanotubecurvature on the adsorption energy for hydrogen has been investigated theoretically by Stan and Cole ${ }^{9}$. TheFeynman ( semiclassical) effective potential approximation was used to calculate the adsorption potential and the amount of hydrogen adsorbed on a $(13,0)$ zigzag nanotube. The adsorption potential was found to be $9 \mathrm{~kJ} \mathrm{~mol}{ }^{-1}$ for hydrogen moleculesinsidethenanotubes at $50 \mathrm{~K}$, about $25 \%$ higher than on the flat surface of graphite. The increase arises

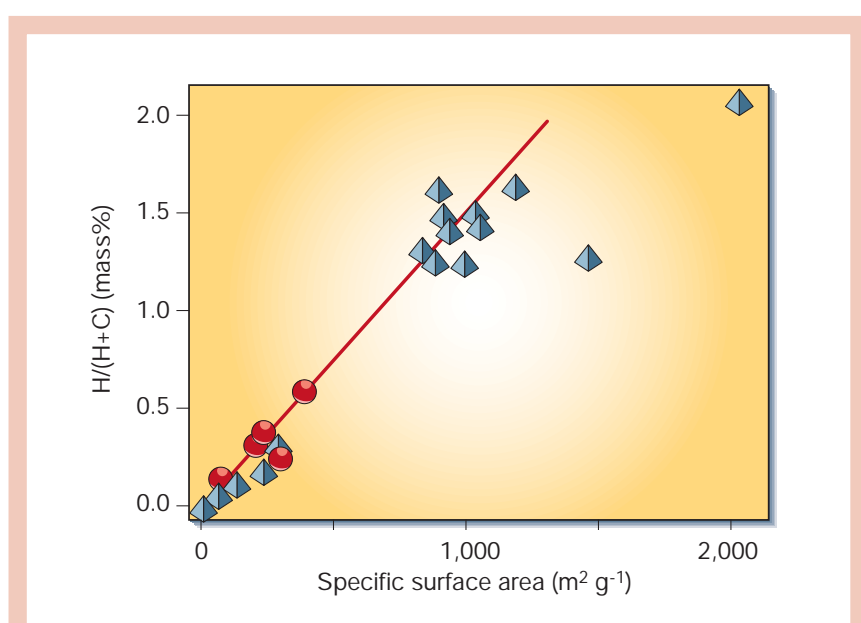

Figure 2 Reversibly stored amount of hydrogen on various carbon materials versus the specific surface area of the samples. Circles represent nanotube samples (best-fit line indicated), triangles represent other nanostructured carbon samples ${ }^{17}$.

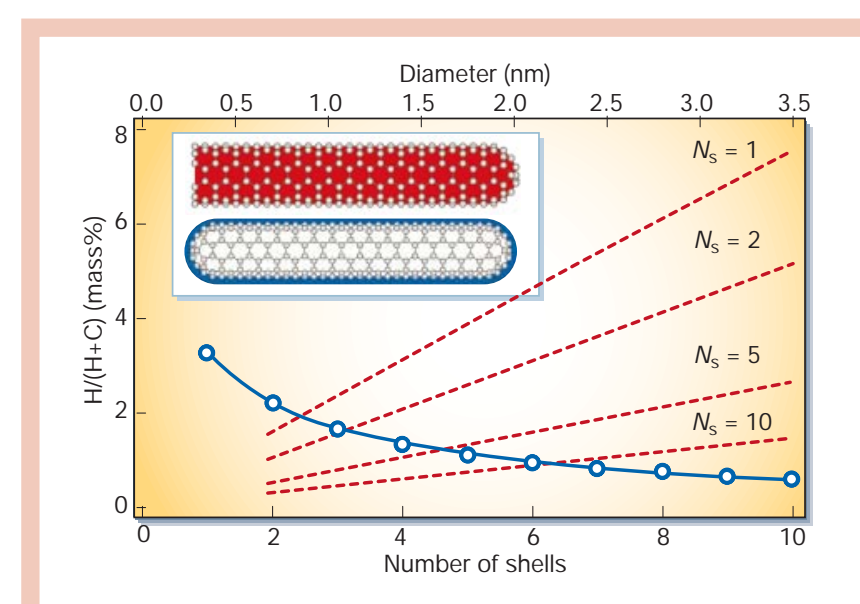

Figure 3 Hydrogen in carbon nanotubes. Calculated storage density in mass\% as a function of the number of shells $N_{s}$ (blue) and as a function of the tube diameter (red). Hydrogen condenses as a monolayer at the surface of the nanotube or condenses in the cavity of the tubes. The condensed hydrogen has the same density as liquid hydrogen at $-253^{\circ} \mathrm{C}$.

from the curvature of the surface and the related higher number of carbon atoms interacting with the hydrogen molecule. At low temperatures, far more hydrogen can be adsorbed in the tube than on a flat surface; but the ratio decreases strongly with increasing temperature, from 55 at $50 \mathrm{~K}$ to 11 at $77 \mathrm{~K}$.

Conflicting results have been published concerning the reversible storage of hydrogen in carbon nanotubes ( see refs 8, 9 for detailed reviews). To a large extent the controversy is caused by insufficient characterization of the carbon material used. It is often a mixture of opened and unopened, single-walled and multi-walled tubes of various diameters and helicities together with other carbonaceous species, just a few of which will be analysed in transmission electron micrographs. To our knowledge, the 'fantastic' results of the Northwestern University group ${ }^{10}$ (morethan 60 mass\% hydrogen in specific carbon fibres) havenot been reproduced elsewhere. H eben et al. ${ }^{11,12}$ still claim to reach 6 -8 mass $\%$ reversible storage (cooling at 1 bar down to liquid nitrogen temperature) in high-purity singlewalled tubes opened by sonication. But $\mathrm{H}$ irscher et al. ${ }^{13}$ revealed that a sonication bar made of titanium alloy results in hydrogen-storing titanium alloy particles in the nanotubematerial; storage was below 1 mass $\%$ when stainlesssteel sonication barswereused. Zuettel etal. ${ }^{14}$ showed by thermal desorption mass spectroscopy that after reaction of carbon nanotubeswith hydrogen at elevated temper atures, hydrocarbons are desorbed. The large mass increase observed by Chen et al. ${ }^{15}$ when carbon nanotubes filled with alkalinemetalswereexposed to hydrogen has been attributed to hydroxideformation ${ }^{16}$.

Nijkamp et al. ${ }^{17}$ have surveyed the storage capacities of a large number of different carbonaceous adsorbents for hydrogen at $77 \mathrm{~K}$ and 1 bar. They concluded that microporousadsorbents, for example zeolites and activated carbons, have appreciablesorption capacities. Optimization of sorbent and adsorption conditions is expected to lead to adsorption of $560 \mathrm{ml} \mathrm{STP} \mathrm{g}^{-1}$, close to targets set for practical use in vehicles. Zuettel et al. ${ }^{18}$ concluded that charging of carbon nanotubes with hydrogen at liquid nitrogen temperature (77 K), or cathodically at ambient conditions, is due to physisorption. The amount of adsorbed hydrogen is proportional to the specific surface area of the carbon nanotube material and limited to 2 mass\% for carbon materials(Fig. 2).

Taking all these results together, we consider it to bescientifically interesting and challenging to continueresearch on theinteraction of hydrogen with different and well-characterized carbon nanostructures. Whether a hydrogen-storage material will emerge from it, however, remainsan open question. 


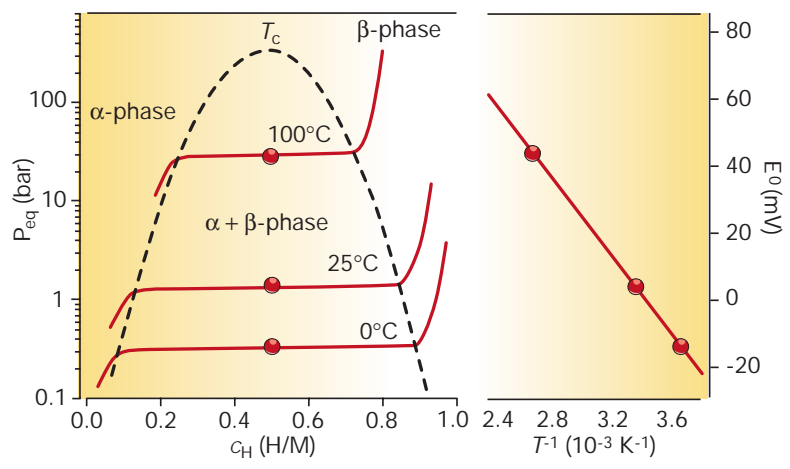

Figure 4 Pressure- concentration- temperature plot and a van't Hoff curve (logarithm of the equilibrium or plateau pressure against the reciprocal temperature); values are for $\mathrm{LaNi}_{5}$. The vertical axes indicate the corresponding hydrogen pressure or the equivalent electrochemical potential. From the slope of the van't Hoff plot, experimental values of the enthalpy of hydride formation $\Delta H$ can be evaluated. The plateau pressure $p_{\mathrm{eq}}(T)$ as a function of temperature is related to the changes $\Delta H$ and $\Delta S$ of enthalpy and entropy, respectively, by the van't Hoff equation: $\ln \left(p_{\text {eq }} / p_{\text {eq }}^{0}\right)=(-\Delta H / R)(1 / T)+\Delta S / R$.

In an interesting sidelineto work ${ }^{19}$ - addressing the potential of metallization and superconductivity of hydrogen, rather than its storage - some hydrogen was reported to be sorbed into graphite intercalation compounds madeof alkaline metals between graphene sheets. Intercalation of hydrogen alone between the graphenelayers in macroscopic structures has never been reported. The dynamic diameter of a freehydrogen molecule $(\mathrm{d}=0.4059 \mathrm{~nm})$ is larger than the interlayer distance in graphite $(d=0.3355 \mathrm{~nm})$, so a significant sizemismatch would haveto beaccommodated upon entry.

\section{Hydrogen storage by metal hydrides}

Many metals and alloys are capable of reversibly absorbing large amounts of hydrogen. Charging can be done using molecular hydrogen gas or hydrogen atoms from an electrolyte. M olecular hydrogen is dissociated atthesurfacebeforeabsorption; two $\mathrm{H}$ atomsrecombineto $\mathrm{H}_{2}$ in the desorption process. The thermodynamic aspects of hydride formation from gaseous hydrogen are described by pressure-composition isotherms(Fig. 4). Thehost metal initially dissolves somehydrogen asa solid solution ( $\alpha$-phase). Asthehydrogen pressure together with theconcentration of $\mathrm{H}$ in themetal isincreased, interactionsbetween hydrogen atomsbecomelocally important, and westart to seenucleation and growth of the hydride $(\beta)$ phase. Whilethe two phases coexist, the isotherms show a flat plateau, the length of which determines how much $\mathrm{H}_{2}$ can bestored reversibly with small pressure variations. In the pure $\beta$-phase, the $\mathrm{H}_{2}$ pressure rises steeply with the concentration. At higher $\mathrm{H}_{2}$ pressure, further plateaux and further hydridephases may beformed. Thetwo-phaseregion endsin acritical point $T_{c}$, abovewhich thetransition from $\alpha$ - to $\beta$-phaseiscontinuous. Theplateau or equilibrium pressure dependsstrongly on temperature and is related to the changes $\Delta \mathrm{H}$ and $\Delta \mathrm{S}$ of enthalpy and entropy, respectively. As the entropy change corresponds mostly to the change from molecular hydrogen gas to dissolved hydrogen, it is roughly $130 \mathrm{~J} \mathrm{~K}^{-1} \mathrm{~mol}^{-1}$ for all metal-hydrogen systems under consideration. The enthal py term characterizes the stability of the metal-hydrogen bond. To reach an equilibrium pressure of 1 bar at $300 \mathrm{~K}, \Delta \mathrm{H}$ should amount to $19.6 \mathrm{~kJ} \mathrm{~mol}_{H}^{-1}$ (ref. 20). The operating temperature of a metal hydridesystem isfixed by theplateau pressurein thermodynamic equilibrium and by theoverall reaction kinetic ${ }^{21}$.

Hydrogen is located in the form of atoms, never molecules, on interstitial sites of the host metal lattice. The lattice expands during hydrogen sorption, often losing some of its high symmetry. As a consequence of the coexistence of the non-expanded $\alpha$-phase and anisotropically expanded $\beta$-phase, lattice defects and internal strain fields areformed, which end in a decrepitation of brittle host metals such as intermetallics. The $\mathrm{H}$ atoms vibrate about their equilibrium position, and perform local motionsand long-rangediffusion.

In terms of electronic structure, the proton acts as an attractive potential to the host metal electrons; electronic bands are lowered in energy and form low-lying bands by hybridization with the hydrogen band, 6-8 eV below theFermi level. TheFermi level itself is shifted, and various phase transitions (metal-semiconductor, magnetic-non-magnetic, reflecting-transparent, order-disorder) may occur. The metal-hydrogen bond offers the advantage of very high hydrogen density at moderate pressure and desorption of all stored hydrogen at thesamepressure.

Which metallic systems are appropriate for hydrogen storage? $M$ any elemental metalsform hydrides, for example $\mathrm{PdH}_{0.6}$, rareearth $\mathrm{REH}_{2}, \mathrm{REH}_{3} \mathrm{Or} \mathrm{M} \mathrm{gH}_{2}$, noneof which arein thepressureand temperature range attractive for mobile storage $\left(1-10 \mathrm{bar}, 0-100^{\circ} \mathrm{C}\right.$, corre sponding to an enthalpy change between 15 and $24 \mathrm{~kJ} \mathrm{~mol}_{\mathrm{H}}{ }^{-1}$ ). The discovery of hydrogen sorption by intermetallic compounds created great hopes and stimulated R\&D efforts worldwide. Well-known compoundsand their propertiesaresummarized in Table2 (ref. 22).

Alloys derived from $\mathrm{LaNi}_{5}$ show some very promising properties, including fast and reversible sorption with small hysteresis, plateau pressure of a few barsat room temperatureand good cycling life. The volumetric hydrogen density (crystallographically) of $\mathrm{LaNi}_{5} \mathrm{H}_{6.5}$ at 2 bar equals that of gaseous molecular hydrogen at 1,800 bar; but advantageously, all the hydrogen desorbs at a pressure of 2 bar. The density for practical purposes is reduced by the packing fraction of $\mathrm{LaNi}_{5}$ powder, but is still above that of liquid hydrogen (Fig. 5). Storagein theseintermetallicsallowsvery safehydrogen handling. But aslanthanum and nickel arelarge elements, the proportion of hydrogen in $\mathrm{LaNi}_{5} \mathrm{H}_{6.5}$ remains below 2 mass\%. Thisisattractivefor electrochemical hydrogen storage in rechargeable metal hydride electrodes, reaching a capacity of $330 \mathrm{~mA} \mathrm{~h} \mathrm{~g}^{-1}$, and produced and sold in more than a billion $\mathrm{AB}_{5}$-typemetal hydridebatteries per year ${ }^{23-25}$.

For gaseous hydrogen fuel tanks to be used in vehicles, however, thisisnot enough. Weneed some4-5 mass\% (indeed, 6.5 mass\% and $62 \mathrm{~kg} \mathrm{H}_{2} \mathrm{~m}^{-3}$ are the targets of the US D epartment of Energy). This low mass density is thegeneral weakness of all known metal hydrides working near room temperature (Fig. 6). Of course, many intermetallic compounds and alloys are known that form hydrides with up to 9 mass\% hydrogen (such as $\mathrm{Li}_{3} \mathrm{Be}_{2} \mathrm{H}_{7} ;$ ref. 26) and $4.5 \mathrm{H}$ atoms per metal atom ( $\mathrm{BaReH}_{9}$; ref. 27), but they are not reversible within therequired range of temperatureand pressure.

When reaction kinetics rather than thermodynamic equilibrium conditions limit the hydride formation and decomposition, various physical and chemical pretreatments can beapplied. Ball milling has the benefits of reducing the grain size, increasing the defect concentration and shortening the diffusion path. Fluorination treatments ${ }^{28}$ arewell suited to render thesurfaceactive, apparently by means of the formation of surface nickel precipitates, the role of which is well known in thehydrogen dissociation process.

$M$ any promising new ideas are under investigation with theclear goal of enhancing the mass density. For example, new families of

\begin{tabular}{|c|c|c|c|c|c|}
\hline Type & Metal & Hydride & Structure & mass $\%$ & $p_{e q}, T$ \\
\hline Elemental & $\mathrm{Pd}$ & $\mathrm{PdH}_{0.6}$ & $\mathrm{Fm} 3 \mathrm{~m}$ & 0.56 & 0.020 bar, $298 \mathrm{~K}$ \\
\hline $\mathrm{AB}_{5}$ & $\mathrm{LaNi}_{5}$ & $\mathrm{LaNi}_{5} \mathrm{H}_{6}$ & $\mathrm{P} 6 / \mathrm{mmm}$ & 1.37 & 2 bar, $298 \mathrm{~K}$ \\
\hline $\mathrm{AB}_{2}$ & $\mathrm{ZrV}_{2}$ & $\mathrm{ZrV}_{2} \mathrm{H}_{5.5}$ & $\mathrm{Fd} 3 \mathrm{~m}$ & 3.01 & $10^{-8} \mathrm{bar}, 323 \mathrm{~K}$ \\
\hline$A B$ & $\mathrm{FeTi}$ & $\mathrm{FeTiH}_{2}$ & Pm3m & 1.89 & 5 bar, $303 \mathrm{~K}$ \\
\hline $\mathrm{A}_{2} \mathrm{~B}$ & $\mathrm{Mg}_{2} \mathrm{Ni}$ & $\mathrm{Mg}_{2} \mathrm{NiH}_{4}$ & P6222 & 3.59 & 1 bar, $555 \mathrm{~K}$ \\
\hline $\begin{array}{l}\text { Body-centred } \\
\text { cubic }\end{array}$ & $\mathrm{TiV}_{2}$ & $\mathrm{TiV}_{2} \mathrm{H}_{4}$ & b.c.c. & 2.6 & 10 bar, $313 \mathrm{~K}$ \\
\hline
\end{tabular}


alloys are being studied in several Japanese laboratories ${ }^{29-31}$ and are included into the national 'Protium' programme. They are based on vanadium, zirconium and titanium as rather electropositive components combined with $3 \mathrm{~d}$ and $4 \mathrm{~d}$ transition metals. Reversible hydrogen-storage capacities approaching 3 mass $\%$ around room temperaturehavebeen reported.

A higher massdensity isreachableonly with light el ementssuch as calcium and magnesium. In fact, $\mathrm{M}$ g formsionic, transparent $\mathrm{M} \mathrm{gH}_{2}$ containing 7.6 mass $\%$ hydrogen. Butitsformation from bulk $\mathrm{M}$ gand gaseous hydrogen is extremely slow, and in thermodynamic equilibrium a plateau pressure of 1 bar requires not room temperature but $300{ }^{\circ} \mathrm{C}$. Different processes have been tried to obtain micro- or nanostructured $\mathrm{M}$ g: precipitations from metal-organic solutions or high-energy ball milling of $\mathrm{M}$ g have proved succesful ways to obtain good charging or discharging kinetics at $150^{\circ} \mathrm{C}$, and the thermodynamics evidently are not affected ${ }^{26,29-31}$. Alloying $\mathrm{Mg}$ before the hydride formation is another approach: $\mathrm{Mg}_{2} \mathrm{Ni}$ forms a ternary complex hydride $\mathrm{M} \mathrm{g}_{2} \mathrm{NiH}_{4}$, which still contains 3.6 mass $\%$ hydrogen. The hydride forms fairly rapidly, probably owing to the presence of $\mathrm{Ni}$ ascatal ystfor thedissociation of molecular hydrogen, but thermodynamically it still requires $280^{\circ} \mathrm{C}$ for 1 bar hydrogen. The alloys $\mathrm{M} \mathrm{g} 2 \mathrm{Cu}, \mathrm{M} \mathrm{g}_{17} \mathrm{La}_{2}$ and $\mathrm{M} \mathrm{gAl}$, and some other known alloys or intermetallic compounds of $\mathrm{Mg}$, react readily ( $\mathrm{MgAl}$ after ball milling) with hydrogen and decomposeinto $\mathrm{M} \mathrm{gH}_{2}$ and another compound or hydride. One example is $\mathrm{Mg}_{2} \mathrm{Cu}+\mathrm{H}_{2}$ which decomposes to $\mathrm{M} \mathrm{gH}_{2}+\mathrm{MgCu}_{2}$. Thereactionsare reversibleat high temperature.

In addition to the enthalpy change of the hydrogen sorption reaction, we now also have to consider the enthalpy change of the host metal system. Could this make $\mathrm{M} \mathrm{g}$-based storage alloys more attractive? If the transformation of the host metal system that accompanies hydrogen desorption is exothermic itself, the net enthalpy of hydrogen desorption becomes smaller. In the systems studied so far ( $\mathrm{Mg}-\mathrm{Cu}, \mathrm{Mg}-\mathrm{Al})$, the temperature for 1 bar equilibrium pressure could belowered from $300^{\circ} \mathrm{C}$ to $280^{\circ} \mathrm{C}$. Thisis not a large improvement, and it has the penalty that the mass density isthereby reduced as well. M agnesium does not form abinary intermetallic compound with iron, but in thepresence of hydrogen it is possible to synthesize the rather stable ternary hydride $\mathrm{M} \mathrm{g}_{2} \mathrm{FeH}_{6}$ with 5.5 mass $\%$ hydrogen ${ }^{26}$.

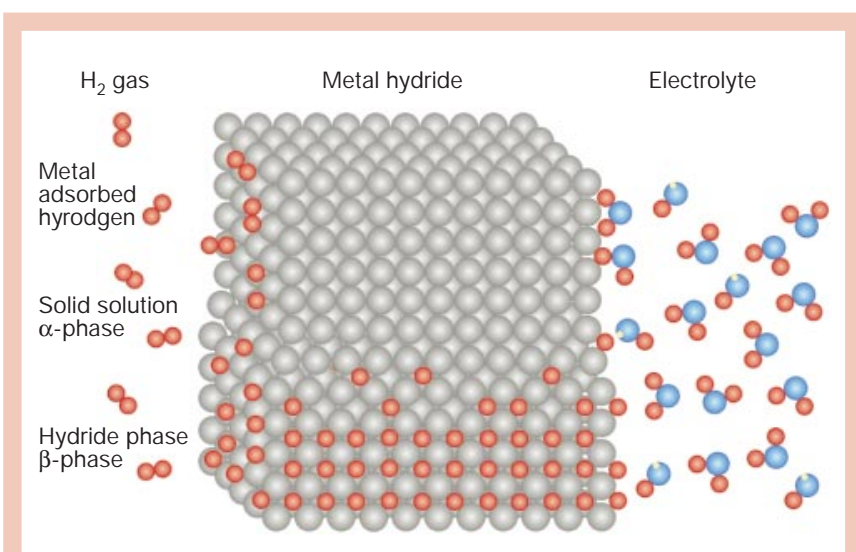

Figure $5 \mathrm{Schematic}$ model of a metal structure with $\mathrm{H}$ atoms in the interstices between the metal atoms, and $\mathrm{H}_{2}$ molecules at the surface. Hydrogen atoms are from physisorbed hydrogen molecules on the left-hand side and from the dissociation of water molecules on the right-hand side.

A different approach is to use composite materials, in which attractive properties of two components are combined to overcome their weaknesses. For instance, magnesium has been ball milled with graphitic carbon or mixed with hydrides showing fast kinetics, such as LaN $\mathrm{i}_{5}$ or $\mathrm{M} \mathrm{g} \mathrm{g}_{2} \mathrm{Ni}$. It comesasno surprise that thecapacities reached values between those of the components, ${ }^{5,26,32}$.

\section{Alanates and other light hydrides}

Some of the lightest elements in the periodic table, for example lithium, boron, sodium and aluminium, form stable and ionic compounds with hydrogen. The hydrogen content reaches values of up to 18 mass\% for $\mathrm{LiBH}_{4}$. However, such compounds desorb the hydrogen only at temperatures from $80^{\circ} \mathrm{C}$ up to $600^{\circ} \mathrm{C}$, and the reversibility of the reaction is not yet cl ear for all systems. Bogdanovic and Schwickardi ${ }^{33}$ showed in 1996 that the decomposition temperature of $\mathrm{NaAlH}_{4}$ can be lowered by doping the hydride with $\mathrm{TiO}_{2}$. The same group showed the reversibility of the reaction

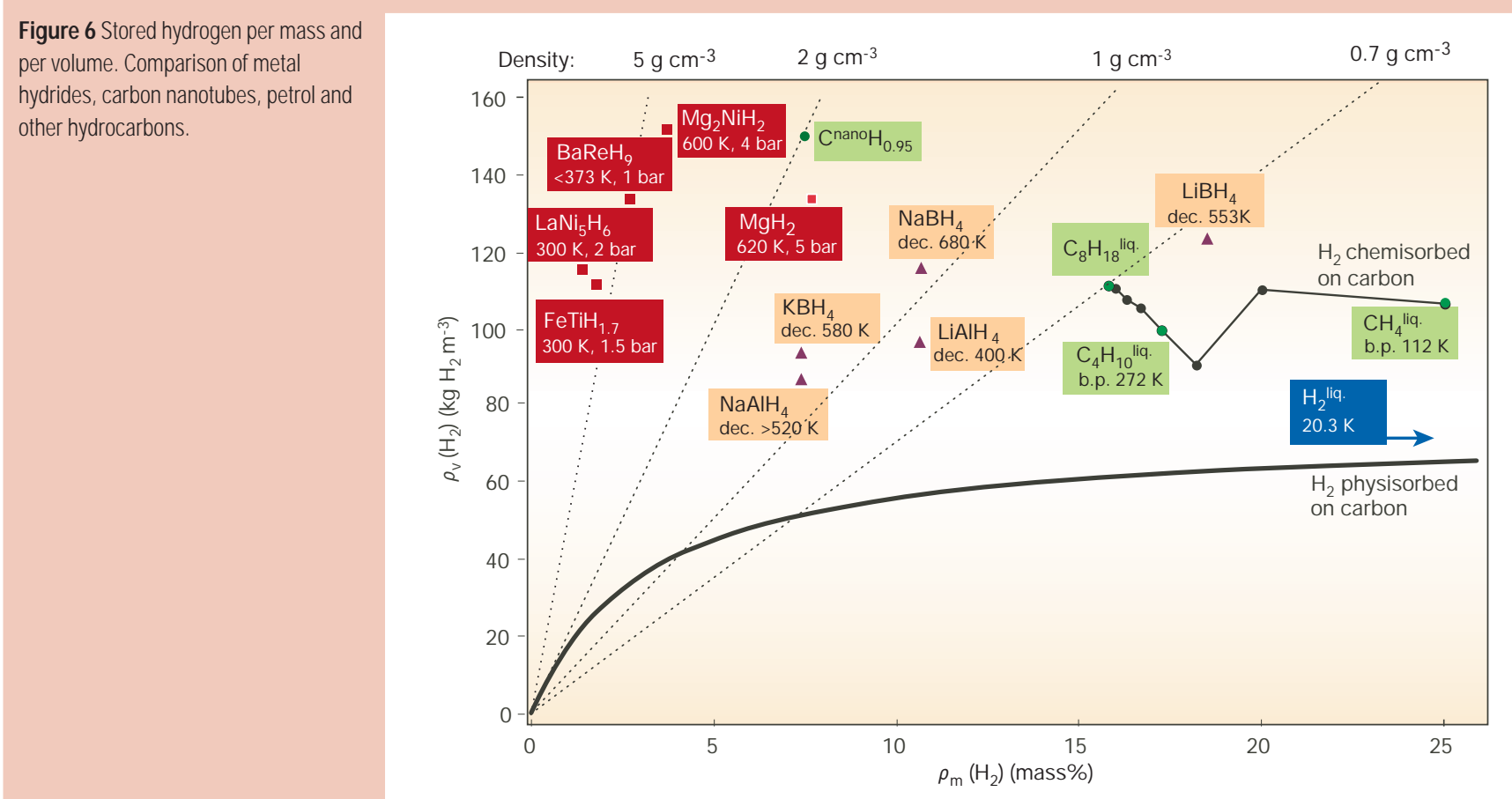


for several desorption/absorption cycles. This is a good example of the potential of such hydrides, which were discovered more than 50 years ago. But several points have to be clarified. First, is the high desorption temperature due to thepoor kinetics of thesystem or due to thethermodynamic stability of thecompound?Thekineticscan be improved by applying an appropriate catalyst to the system and apparently also by ball milling and the introduction of defects. Second, what are the conditions for a reversible reaction - for example, formation and stabilization of clusters of an intermetallic compound of theremaining metals on desorption?Third, what isthe desorption reaction and what aretheintermediatereaction products (decomposition in several steps)?

Assuming that these questions can be answered, what would be theroleof light hydridesin an on-board fuel cell? Theexhaust gas of a fuel cell is water vapour, which could becollected and reused for onboard hydrogen production. The common experiment - shown in many chemistry classes - wherea small piece of sodium floating on water produces hydrogen, demonstrates such a process. The sodium is transformed to sodium hydroxide in this reaction. The reaction is not reversible, but the sodium hydroxide could later be removed and reduced in a solar furnace back to sodium. Each sodium atom produces one hydrogen atom, so the corresponding gravimetric hydrogen density of the sodium reaction is slightly more than 4 mass $\%$. Lithium used in thesameway would deliver up to 14 mass $\%$ of hydrogen. The alkali metals as a hydrogen source are easy to han$\mathrm{dle}$, and a car could be refilled within a few minutes. To deliver the necessary $4 \mathrm{~kg}$ of hydrogen using the water produced in the fuel cell would take $28 \mathrm{~kg}$ of lithium. After using up all the hydrogen thetank would contain $99 \mathrm{~kg}$ of lithium hydroxide, ready to berecycled.

\section{Visions for the future}

Road traffic islikely to increaseeven more. Mustroad vehicleshaveto satisfy human prestige, and do we need a strong and heavy vehicle cage to protect drivers and passengers from being injured in case of inevitable mistakes? As soon as wireless, electronic control systems are installed to help to avoid crashes, much lighter and moreenergyefficient vehicles will bebuilt in countries that do not consider energy availability to be unlimited. In Europe and Japan, there are already small and lightweight cars availablewith a combustion engine using as little as $3 \mathrm{l}$ of petrol per $100 \mathrm{~km}$ (that is, less than half the amount used by conventional, widely used cars). Four kilograms of hydrogen are enough to run $400 \mathrm{~km}$ with a combustion engine, and only $2 \mathrm{~kg}$ hydrogen for amodern car driven by afuel cell.

The new joint venture of Shell, GfE and Hydro-Québec ${ }^{3}$ on hydrogen storage using metal hydrides, and the fact that no comparable economic effort on hydrogen storage in carbon nanostructures exists, can be taken as clear signs in favour of the metal- hydrogen systems. Thereis reason for hopethat one day much better hydrogen-storagematerials will bediscovered and developed, rather as we have seen a revolution in high-temperature superconducting materialsor hard permanent magnets. Wemustbear in mind that to develop a sustainable futureenergy policy requires us to focus not only on the scientific and technical challenge, but also on vital adaptations bythesocioeconomic system and achangein attitudesto energy. Sustainability - and humanity - will profit if the price we pay for energy includes costs for long-term production, transport and distribution of energy, materials, and restoration of thedamaged environment.

1. Winter, C. J. \& Nitsch, J. H ydrogen as an Energy Carrier: Technologies, Systems, Economy (Springer, 1988)

2. Bain, A. \& Van Vorst, W. D. Int. J. Hydrogen Energy 24, 399-403 (1999).

3. Shell Hydrogen, Hydro-Québec (HQ) \& Gesellschaft für Elektrometallurgie(GfE). Hydrogen storage joint venture to be established. <http://www.shell.com>Press release(12-07-2001).

4. Nellis, W. J., Louis, A. A.\& Ashcroft, N. W. M etallization of fluid hydrogen. Phil. Trans. R. Soc. Lond. A 356, 119-135 (1998)

5. Orimo, S.-I. et al. Hydrogen in the mechanically prepared nanostructured graphite. Appl. Phys. Lett. 75, 3093 (1999)

6. Orimo, S., M atsushima, T., Fujii, H., Fukunaga, T. \& M ajer, G. Defectivecarbon for hydrogen storage- thermal desorption property of themechanically prepared nanostructured graphite. J Appl. Phys. (in the press).

7. Stan, G. \& Cole, M. W. Hydrogen adsorption in nanotubes. J. Low Temp. Phys. 120,539-544 (1998)

8. Hirscher, M. (ed.) Hydrogen storage in nanoscalecarbon and metals. Appl. Phys. A (special issue) $\mathbf{7 2}$ 2(2001).

9. Sholl, C. A.\& Gray, E. M acA. (eds) Proc. Int. Symp. Metal Hydrogen Systems- Fundamentals and Applications, Noosa, Australia, 1-60 ctober 2000. J. Alloys Compounds (in the press).

10. Chambers, A., Park, C., Baker, R. T. K. \& Rodriguez, N. M . Hydrogen storagein graphitenanofibers. Phys. Chem. B 102, 4253-4256 (1998).

11. Dillon, A. C. et al. Storage of hydrogen in single-walled carbon nanotubes. Nature 386, 377-379 (1997)

12. Dillon, A. C. et al. Carbon nanotubematerials for hydrogen storage. Proc. 2000 D OE/NREL Hydrogen program review, 8-10 M ay 2000.

13. Hirscher, M . et al. Hydrogen storagein sonicated carbon materials. Appl. Phys. A 72, 129-132 (2001).

14.Züttel A. et al. Hydrogen sorption by carbon nanotubes and other carbon nanostructures. J. Alloys Compounds (in the press).

15. Chen, P., Wu, X., Lin, J. \& Tan, K. L. High $\mathrm{H}_{2}$ uptakeby alkali-doped carbon nanotubes under ambient pressure and moderatetemperatures. Science $\mathbf{2 8 5}, 91-93$ (1999).

16. Hirscher, M . et al. Hydrogen storage in carbon nanostructures. J. Alloys Compounds (in the press).

17. Nijkamp, M. G., Raaymakers, J. E. M. J., Van Dillen, A. J. \& De Jong, K. P. Hydrogen storage using physisorption-materials demands. Appl. Phys. A $\mathbf{7 2}, 619-623$ (2001).

18.Züttel, A. et al. Hydrogen storage in carbon nanostructures. Int. J.Hydrogen Energy (in the press).

19. Enoki, T., Shindo, K. \& Sakamoto, N. Electronic properties of alkali-metal-hydrogen-graphite intercalation compounds. Z. Phys. Chem. 181, 75-82 (1993).

20. Schlapbach, L. (ed.) Hydrogen in Intermetallic CompoundsI. Electronic, Thermodynamic, and Crystallographic Properties, Preparation (Topicsin Applied Physics Vol. 63) (Springer, 1988)

21. Schlapbach, L. (ed.) Hydrogen in Intermetallic CompoundsII. Surfaceand Dynamic Properties, Applications (Topicsin Applied Physics Vol. 67) (Springer, 1992).

22. Sandrock, G. \& Thomas, G. The IEA/D OC/SN L on-linehydride databases. Appl. Phys. A $\mathbf{7 2}$, 153-155 (2001).

23. Sakai, T., Natsuoka, M . \& I wakura, C. Rare earth intermetallics for metal-hydrogen batteries. Handb. Phys. Chem. RareEarths 21, 135-180 (1995).

24. Latroche, M., Percheron-Guegan, A. \& Chabre, Y. Influence of cobalt content in $\left.\mathrm{M} \mathrm{mNi}_{4,3-x}\right) \mathrm{M} \mathrm{n}_{0.3} \mathrm{Al}_{0.4} \mathrm{Co}_{x}$ alloy ( $\mathrm{x}=0.36$ and 0.69 ) on its electrochemical behaviour studied by in situ neutron diffraction. J. Alloys Compounds 295, 637-642 (1999).

25. Schlapbach, L., Felix M eli, F., Züttel, A., Westbrook, J. H . \& Fleischer, R. L. (eds) in Intermetallic Compounds: Principles and PracticeVol. 2, Ch. 22 (Wiley, 1994).

26. Zaluska, A., Zaluski, L. \& Stroem-O Isen, J. O. Structure, catalysis and atomic reactions on thenanoscale: a systematic approach to metal hydrides for hydrogen storage. Appl. Phys. A R2, 157 (2001)

27. Yvon, K. Complex transition metal hydrides. Chimia 52,613-619 (1998).

28. Liu, F. J. \& Suda, S. A method for improving thelong-term storability of hydriding alloys by air water exposure. J. Alloys Compounds 231, 742-750 (1995).

29. A kiba, E. \& I ba, H. Hydrogen absorption by Laves phase related BCC solid solution. Intermetallics 6 , 461-470 (1998).

30. Kuriiwa, T. et al. New V-based alloys with high protium absorption and desorption capacity. J. Alloys Compounds 295, 433-436 (1999)

31. Tsukahara, M . et al. Hydrogen storage and electrode properties of V-based solid solution typealloys prepared by a thermic process. J. Electrochem. Soc. 147,2941-2944 (2000).

32. Inoue, $\mathrm{H}$. et al. Effect of ball-milling with $\mathrm{Ni}$ and Raney $\mathrm{Ni}$ on surface structural characteristics of TiV2.1Ni0.3 alloy. J. Alloys Compounds 325, 299-303 (2001)

33. Bogdanovic, B. \& Schwickardi, M. Ti-doped alkali metal aluminium hydrides as potential novel reversiblehydrogen storage materials. J. Alloys Compounds 253, 1-9 (1997).

\section{Acknowledgements}

Wethank theSwissFederal Office of Energy (BFE), in contract with IEA, the Swiss Federal Office of Education and Science(BBW), and theUniversity of Fribourg and EM PA for support of our hydrogen-storage research projects. 